\title{
Secretory leukocyte protease inhibitor promotes differentiation and mineralization of MC3T3-E1 preosteoblasts on a titanium surface
}

\author{
BAIK-DONG CHOI ${ }^{1 *}$, SEUNG-YEON LEE ${ }^{1 *}$, SOON-JEONG JEONG ${ }^{2}$, DO-SEON LIM ${ }^{3}$, \\ HEE-JAE CHA ${ }^{4}$, WON-GYUN CHUNG ${ }^{5}$ and MOON-JIN JEONG ${ }^{1}$
}

\author{
${ }^{1}$ Department of Oral Histology and Developmental Biology, School of Dentistry, Chosun University, Gwangju 501-759; \\ ${ }^{2}$ Department of Dental Hygiene, Youngsan University, Yangsan, Gyeongsangnam-do 626-790; \\ ${ }^{3}$ Department of Dental Hygiene, Eulji University, Seongnam, Gyeonggi 461-713; \\ ${ }^{4}$ Department of Parasitology and Genetics, College of Medicine, Kosin University, Busan 602-072; \\ ${ }^{5}$ Department of Dental Hygiene, Wonju College of Medicine, Yonsei University, Wonju, Gangwon 220-701, Republic of Korea
}

Received April 17, 2015; Accepted March 8, 2016

DOI: $10.3892 / \mathrm{mmr} .2016 .5381$

\begin{abstract}
Mineralized bone matrix constituted with collagenous and non-collagenous proteins was synthesized by osteoblasts differentiated from mesenchymal stem cells. Secretory leukocyte protease inhibitor (SLPI), a serine protease inhibitor, promotes cell migration and proliferation, and suppresses the inflammatory response. Recent studies reported that SLPI regulates the formation of dentin and mineralization by odontoblasts and increases the adhesion and viability of preosteoblasts on a titanium (Ti) surface. Ti and its alloys are widely used implant materials in artificial joints and dental implants owing to their biocompatibility with bone. Therefore, this study aimed to examine whether SLPI can be an effective molecule in promoting differentiation and mineralization of osteoblasts on a Ti surface. In order to investigate the effects of SLPI on osteoblasts, an MTT assay, PCR, western blotting and Alizarin Red S staining were performed. The results demonstrated that SLPI increased the viability of osteoblasts during differentiation on Ti discs compared with that of the control. The expression levels of SLPI mRNA and protein were higher than that of the control after treatment of osteoblasts with SLPI on Ti discs during differentiation. SLPI increased the formation of mineralized nodules and mRNA expression of alkaline phosphatase, dentin sialophosphoprotein, dentin matrix protein 1, bone sialoprotein,
\end{abstract}

Correspondence to: Professor Moon-Jin Jeong, Department of Oral Histology and Developmental Biology, School of Dentistry, Chosun University, 309 Pilmun-Daero, Dong-Gu, Gwangju 501-759, Republic of Korea

E-mail: mjjeong@chosun.ac.kr

*Contributed equally

Key words: secretory leukocyte protease inhibitor, differentiation, mineralization, preosteoblast, titanium and collagen I in osteoblasts on Ti discs compared with that of the control. In conclusion, SLPI increases the viability and promotes the differentiation and mineralization of osteoblasts on Ti surfaces, suggesting that SLPI is an effective molecule for achieving successful osseointegration between osteoblasts and a Ti surface.

\section{Introduction}

Osteoblasts, which are formed from the differentiation of preosteoblasts derived from mesenchymal cells, are responsible for the formation of bone matrix and mineralization. At the early stages of osteoblast differentiation, gene expression associated with the formation of bone matrix, such as type I collagen (Col I), osteocalcin (OCN) and alkaline phosphatase (ALP) are increased. Secreted extracellular matrix is mineralized by calcium deposition at later stages of osteoblast differentiation (1). Non-collagenous proteins, such as dentin sialoprotein (DSP) and dentin phosphoprotein (DPP), which are cleaved from dentin sialophosphoprotein (DSPP), dentin matrix protein 1 (DMP-1), and bone sialoprotein (BSP) are important in osteoblast differentiation and mineralization (2).

Osseointegrated implants have been used for a long time in orthopedics and prosthetic dentistry for the restoration of damaged bone and loss of function. These implant materials are made of titanium (Ti) and its alloy due to its mechanical properties and good biocompatibility (3). Successful dental implants undergo osseointegration properly around the $\mathrm{Ti}$ surface; however, the release the metal ions from the implant, as well as patients suffering from underlying diseases, such as osteoporosis, diabetes, and periodontitis, can cause the implant to fail (4). Therefore, several studies have been performed to increase osteoblast adhesion and differentiation through chemical and physical changes in Ti surface structure or by producing alloys with other metals. Ti-zirconia or Ti-niobium alloys increase the expression of genes associated with the differentiation of osteoblasts. In addition, oxidization of the Ti surface promotes the differentiation of osteoblasts (5). 
Furthermore, bone morphogenic protein-2 (BMP-2) increases the ALP activity with the secretion of OCN and osteoprotegerin, and promotes the differentiation of osteoblasts on the $\mathrm{Ti}$ surface (6).

SLPI is an $11.7-\mathrm{kDa}$ cysteine-rich protein. It is an epithelial cell product found in the uterine cervix, nasal mucus, bronchial mucus, saliva, and seminal plasma (7). SLPI acts as an anti-inflammatory factor in the early inflammatory response of odontoblasts (8). A recent study reported that SLPI accelerates the adhesion and migration of MC3T3-E1 cells on Ti surfaces by increasing the formation of actin stress fibers, paxillin expression and focal adhesion kinase phosphorylation (9). Conversely, there are no studies regarding the effect of SLPI on the differentiation and mineralization of osteoblasts on a Ti surface. Therefore, the aim of the present study was to determine the function of SLPI on the gene expression associated with the differentiation and mineralization of osteoblasts on Ti surfaces.

\section{Materials and methods}

Ti samples. Two types of Ti discs, 20 and $48 \mathrm{~mm}$ in diameter and $2 \mathrm{~mm}$ in thickness, were used. Commercially pure titanium (Cp-Ti) discs were kindly provided by Professor Han-Cheol Choe (Department of Dental Materials, School of Dentistry, Chosun University, Gwangju, Republic of Korea). Polished Cp-Ti discs were prepared using a method described previously (9).

Cell culture and differentiation with SLPI. MC3T3-E1 cells (American Type Culture Collection, Manassas, VA, USA), an osteoblastic cell line derived from mouse calvaria, were cultured in $\alpha$-modified Eagle's medium ( $\alpha$-MEM; Gibco; Thermo Fisher Scientific, Inc., Waltham, MA, USA) containing $10 \%$ fetal bovine serum (WelGENE, Daegu, Korea) and 1\% antibiotic-antimycotic solution (containing penicillin, streptomycin and amphotericin B; WelGENE) according to the manufacturer's recommendations. The cells were transferred to a Ti surface and changed to a differentiation medium ( $\alpha$-MEM supplemented with 5\% FBS, $10 \mathrm{mM} \beta$-glycerol phosphate and $50 \mu \mathrm{g} / \mathrm{ml}$ ascorbic acid) with or without $1 \mu \mathrm{g} / \mathrm{ml}$ recombinant human (rh)SLPI (R\&D Systems, Minneapolis, MN, USA) after $24 \mathrm{~h}$. The cells were placed into a humidified chamber and maintained in an atmosphere containing $5 \% \mathrm{CO}_{2}$ at $37^{\circ} \mathrm{C}$.

Cell viability assay. Cell viability was assessed using a 3-(4,5 dimethylthiazol-2-yl)-2,5-diphenyltetrazoliumbromid (MTT) assay. The MC3T3-E1 cells plated on the Ti discs $\left(6 \times 10^{5}\right.$ cells $\left./ \mathrm{ml}\right)$ were incubated for 4, 7 and 10 days in differentiation medium with or without rhSLPI. An MTT assay (Sigma-Aldrich, St. Louis, MO, USA) was performed to examine the cell viability as described previously (9).

Extraction of total RNA and semi-quantitative reverse-transcription polymerase chain reaction $(R T-P C R)$. The MC3T3-E1 cells plated on the Ti discs $\left(1 \times 10^{6}\right.$ cells $\left./ \mathrm{ml}\right)$ were incubated for 4, 7 and 10 days in differentiation medium with or without rhSLPI. The total RNA was extracted from the cells using TRI reagent (MRC Inc., Houston, TX, USA) according to the manufacturer's instructions. Total RNA was quantified using an ultraviolet (UV) spectrophotometer (Ultrospec 2000;
GE Healthcare, Little Chalfont, UK). A 1- $\mu \mathrm{g}$ sample of total RNA was used to synthesize the cDNA. The mRNA was incubated at $50^{\circ} \mathrm{C}$ for $1 \mathrm{~h}$ and at $70^{\circ} \mathrm{C}$ for 10 min using Hyperscript RT premix (GeneAll Biotechnology Co. Ltd., Dongnam-ro, Korea). The PCR reaction was conducted in a thermocycler (TP600; Takara Bio Inc., Otsu, Japan) after adding $1 \mu \mathrm{l}$ of cDNA and the gene specific primers to the $\alpha$-Taq premix (2U Taq DNA polymerase, $200 \mu \mathrm{M}$ deoxynucleotide triphosphate mixture and $2.5 \mathrm{mM} \mathrm{MgCl}_{2}$; GeneAll Biotechnology). The mouse gene specific primers were designed using the nucleotide sequences of SLPI, ALP, DSPP, DMP1, BSP, Col I, and glyceraldehyde 3-phosphate dehydrogenase (GAPDH).

The following primers were used for PCR amplification: SLPI forward, 5'-TGC TTA ACC CTC CCA ATG TC-3' and reverse, 5'-AAT GCT GAG CCA AAA GGA GA-3'; ALP forward, 5'-AAG ACG TGG CGG TCT TTG C-3' and reverse, 5'-GGG AAT CTG TGC AGT CTG TG-3'; DSPP forward, 5'-CGA CCC TTG TCC AGG A-3' and reverse, 5'-CAT GGA CTC GTC ATC GAA-3'; DMP1 forward, 5'-CGA GTC TCA GGA GGA CA-3' and reverse, 5'-CTG TCC TCC TCA CTG GA-3'; BSP forward, 5'-ACC GGC CAC GCT ACT TTC TTT AT-3' and reverse, 5'-TCC TCG TCG CTT TCC TTC ACT TT-3'; Col I forward, 5'-ATT CGG AGC TCA AGA TGT AA-3' and reverse, 5'-CAG TCA AGT CCT AGC CAA AC-3'; GAPDH forward, 5'-CCA TGG AGA AGG CTG GG-3' and reverse, 5'-CAA AGT TGT CAT GGA TGA CC-3'. All primers were synthesized by Bioneer (Daejeon, Korea). Each PCR reaction protocol consisted of an initial denaturation at $95^{\circ} \mathrm{C}$ for 2 min followed by three-step cycling: Denaturation at $95^{\circ} \mathrm{C}$ for $20 \mathrm{sec}$, annealing for $10 \mathrm{sec}$ at a temperature optimized for each primer pair and extension at $72^{\circ} \mathrm{C}$ for $30 \mathrm{sec}$. The gene-specific conditions were as follows: SLPI, $60^{\circ} \mathrm{C}$ and 30 cycles; ALP, $62^{\circ} \mathrm{C}$ and 30 cycles; DSPP, $56^{\circ} \mathrm{C}$ and 35 cycles; DMP $1,55^{\circ} \mathrm{C}$ and 35 cycles; BSP, $60^{\circ} \mathrm{C}$ and 30 cycles; Col I, $50^{\circ} \mathrm{C}$ and 35 cycles; and GAPDH, $56^{\circ} \mathrm{C}$ and 30 cycles respectively, After the required number of cycles (30-35), the reactions underwent a final extension at $72^{\circ} \mathrm{C}$ for $5 \mathrm{~min}$. GAPDH was used as the internal control.

All PCR products were electrophoresed on $1.5 \%$ or $2 \%$ agarose gels (Takara Bio Inc.) buffered with $0.5 \mathrm{X}$ Tris-borateethylenediamine tetraacetate and stained with ethidium bromide (GeNet Bio, Daejeon, Korea) after amplification. The staining bands were visualized using Gel-Doc (Bio-Rad Laboratories, Inc., Hercules, CA, USA). The intensities of the bands were measured and quantified using Science Lab Image Gauge software (version 3.12; Fuji Film, Tokyo, Japan) as described previously (10).

Western blot analysis. Differentiated MC3T3-E1 cells $\left(1 \times 10^{6}\right.$ cells $\left./ \mathrm{ml}\right)$ with or without SLPI for 4, 7 and 10 days were harvested and the protein was extracted using Nonidet $\mathrm{P}$ (NP)-40 lysis buffer [150 mM NaCl, 1\% NP-40, $50 \mathrm{mM}$ Tris- $\mathrm{HCl}$ (pH 7.4), $2 \mathrm{mM} \mathrm{Na}_{3} \mathrm{VO}_{4}, 2 \mathrm{mM} \mathrm{Na}_{4} \mathrm{P}_{2} \mathrm{O}, 50 \mathrm{mM} \mathrm{NaF}$, $2 \mathrm{mM}$ ethylenediamine tetraacetic acid, $0.1 \mu \mathrm{g} / \mathrm{ml}$ leupeptin and $1 \mu \mathrm{g} / \mathrm{ml}$ aprotinin; BioShop Co., Burlington, ON, Canada]. The extracted protein was incubated using a Dc protein assay kit (Bio-Rad Laboratories, Inc.) and the protein concentration was determined using a UV spectrophotometer (EL311; BioTek Instruments, Winooski, VT, USA). A total of $20 \mu \mathrm{g}$ of protein per lane was subjected to $15 \%$ SDS-polyacrylamide gel (Bio- 
Rad Laboratories, Inc.) electrophoresis and separated proteins were then transferred to a polyvinylidene difluoride membrane (Merck Millipore, Darmstadt, Germany). Following blocking with 5\% non-fat dry milk in $20 \mathrm{mM}$ Tris (pH 7.4), $150 \mathrm{mM} \mathrm{NaCl}$ and $0.1 \%$ Tween-20 (TBS-T) for $1 \mathrm{~h}$ at room temperature, the membrane was probed with the following primary antibodies at 1:1,000 dilution at $4^{\circ} \mathrm{C}$ for $16 \mathrm{~h}$ : Mouse anti- $\beta$-actin (cat. no. sc-47778; Santa Cruz Biotechnology, Inc., Dallas, TX, USA) or rabbit anti-mouse SLPI antibody provided by Takara Bio Inc. via their custom antibody service (order no. ARP4093; selective for the peptide sequence EGGKNDAIKIGAC in the polypeptide region of the mouse SLPI protein) (8). The membrane was then blotted with horseradish peroxidase (HRP)-conjugated goat anti-rabbit or goat anti-mouse (cat. no. sc-2004 or sc-2005, respectively; 1:5,000 dilution; Santa Cruz Biotechnology Inc.). The membrane was washed four times for $10 \mathrm{~min}$ each at room temperature in TBS-T after treatment with the primary and secondary antibodies, respectively. $\beta$-actin was used as the internal control. Blots were developed by treatment with an enhanced chemiluminescence solution (Luminata Crescendo Western HRP substrate; Merck Millipore) and images were captured on X-ray film (Fuji Film, Tokyo, Japan). The density of the expressed bands was measured using a Science Lab Image Gauge (version 3.12; Fuji Film).

Alizarin Red S staining. To identify the formation of mineralized nodules following MC3T3-E1 cell differentiation on Ti surfaces, the cells were stained with 2\% Alizarin Red S (Sigma-Aldrich). Mineralized nodules were observed using a stereoscopic microscope (Stemi 2000-C, Carl Zeiss, Oberkochen, Germany). The Alizarin Red S-stained MC3T3-E1 cells were incubated with cetylpyridinium chloride (Acros Organics; Thermo Fisher Scientific, Inc.) to dissolve and release calcium-bound Alizarin Red S into the solution. The absorbance of Alizarin Red S released was measured at $562 \mathrm{~nm}$ using a microplate reader (BioTek Instruments, Inc., Winooski, VT, USA).

Statistical analysis. All experiments were conducted in triplicate. All data is reported as the mean \pm standard deviation determined using Excel 2010 statistical software (Microsoft, Redmond, WA, USA). $\mathrm{P}<0.05$ and $\mathrm{P}<0.01$ were considered to indicate a statistically significant difference. The significant differences were determined using an unpaired Student's t-test.

\section{Results}

Proliferation of SLPI-treated MC3T3-E1 cells during differentiation on Ti discs. The viability of SLPI-treated MC3T3-E1 cells was 1.1 and 1.4 times higher than that of the untreated cells at 4 and 7 days, respectively, during differentiation on a Ti disc $(\mathrm{P}<0.05$ and $\mathrm{P}<0.01$; Fig. 1). However, no difference in cell viability between untreated and SLPI-treated cells was observed at day 10 of differentiation on the Ti disc.

SLPI $m R N A$ and protein expression in SLPI-treated MC3T3-E1 cells during differentiation on Ti discs. SLPI mRNA expression in the SLPI-treated MC3T3-E1 cells was 1.7 and 2.8 times higher than that of the untreated cells at 4 and 7 days, respectively, during differentiation on a Ti disc $(\mathrm{P}<0.01$; Fig. 2A). However, no difference in expression of

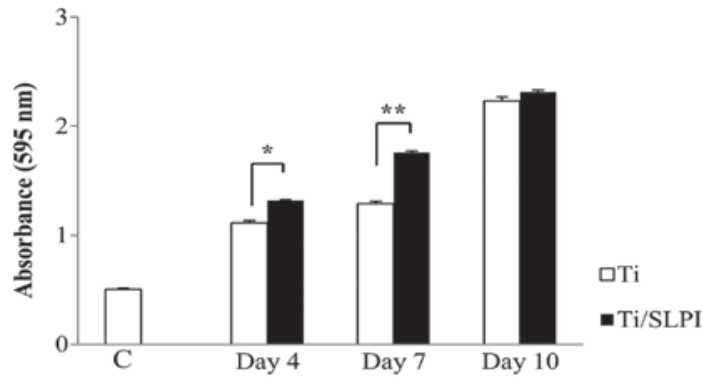

Figure 1. Viability of the SLPI-treated MC3T3-E1 cells during differentiation on Ti discs. SLPI increased the cell viability (day 4 and 7) of MC3T3-E1 cells significantly during differentiation compared to that of the untreated cells on Ti disc. ${ }^{*} \mathrm{P}<0.05$ and ${ }^{* * *} \mathrm{P}<0.01$. Ti, titanium; SLPI, secretory leukocyte protease inhibitor; C, undifferentiated MC3T3-E1 cells without SLPI treatment on Ti discs (control)

SLPI mRNA between untreated and SLPI-treated cells was observed at day 10 of differentiation on the Ti disc. SLPI protein expression in the SLPI-treated MC3T3-E1 cells was 1.4, 2.4 and 1.5 times higher than that of the untreated cells at 4, 7 and 10 days, respectively, during differentiation on a Ti $\operatorname{disc}(\mathrm{P}<0.01$; Fig. 2B)

Mineralization of SLPI-treated MC3T3-E1 cells during differentiation on a Ti disc. Alizarin Red S staining showed that the SLPI-treated MC3T3-E1 cells increased the level of mineral deposition compared with that of the untreated cells during differentiation on a Ti disc (Fig. 3A). The mineralized nodule formation in the SLPI-treated MC3T3-E1 cells was 1.3 and 1.8 times higher than that of the untreated cells at 4 and 10 days, respectively, during differentiation on a $\mathrm{Ti} \operatorname{disc}(\mathrm{P}<0.05$; Fig. 3B). However, at day 7 of differentiation, no difference in the mineralized nodule formation was observed between untreated and SLPI-treated cells.

$A L P$, non-collagenous and collagenous gene expression in SLPI-treated MC3T3-E1 cells during differentiation on Ti discs. RT-PCR analysis showed that ALP, DSPP, DMP-1, BSP, and Col I mRNA expression was higher in the SLPI-treated MC3T3-E1 cells compared with that of the untreated cells during differentiation on a Ti disc (Fig. 4A). ALP mRNA expression in the SLPI-treated MC3T3-E1 cells was higher than that of the untreated cells at 4,7 and 10 days during differentiation on a Ti disc. The DSPP and Col I mRNA expression in the SLPI-treated MC3T3-E1 cells were higher than that of the untreated cells at 4 and 7 days during differentiation on a Ti disc. The DMP1 and BSP mRNA expression in the SLPI-treated MC3T3-E1 cells was higher than that of the untreated cells at 7 days during differentiation on a Ti-disc $(\mathrm{P}<0.05$ and $\mathrm{P}<0.01$, respectively; Fig. 4B).

\section{Discussion}

The cytotoxicity of the ions released from various metallic implant materials, including $\mathrm{Ti}$, results in decreases in the proliferation of osteoblasts (11). In addition, Ti-particles decrease the cell viability through the promotion of apoptosis (12). A recent study reported that SLPI increases the proliferation of oral keratinocytes and it was reported to be an 
A
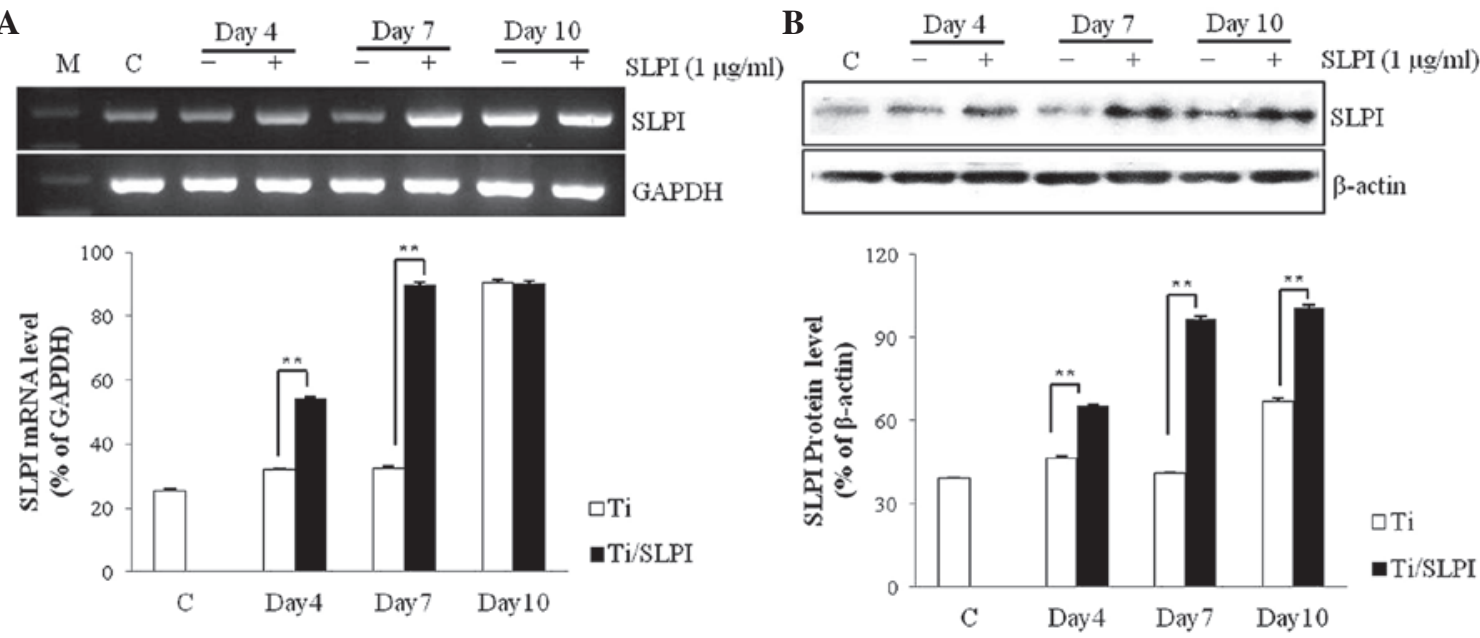

Figure 2. SLPI mRNA and protein expression of SLPI-treated MC3T3-E1 cells during differentiation on Ti discs. (A) SLPI mRNA was increased in the SLPI-treated MC3T3-E1 cells compared with that of the untreated cells during differentiation on a Ti disc (days 4 and 7). (B) SLPI protein was increased at 4, 7 and 10 days in MC3T3-E1 cells compared to that of the untreated cells during differentiation on a Ti disc ( $(" \mathrm{P}<0.01)$. SLPI, secretory leukocyte protease inhibitor; M, marker; Ti, titanium; GAPDH, glyceraldehyde 3-phosphate dehydrogense; C, undifferentiated MC3T3-E1 cells without SLPI treatment on Ti discs (control).

A

A Con

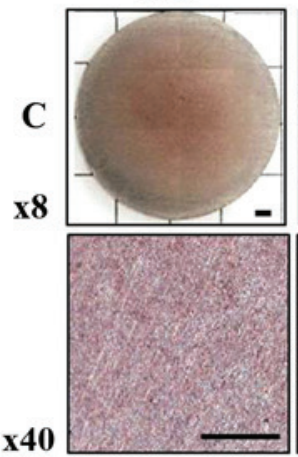

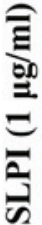

Day 4
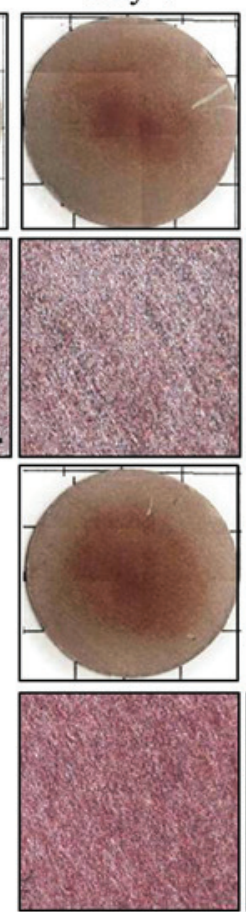

Day 7
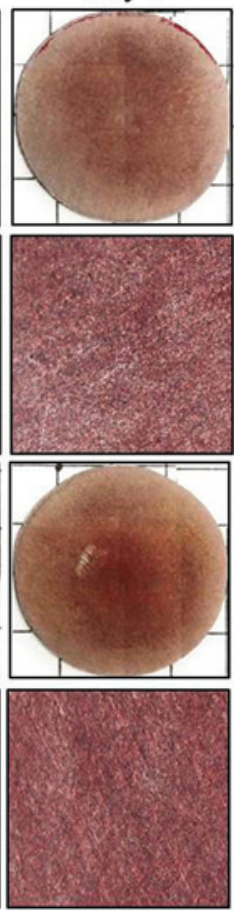

Day 10
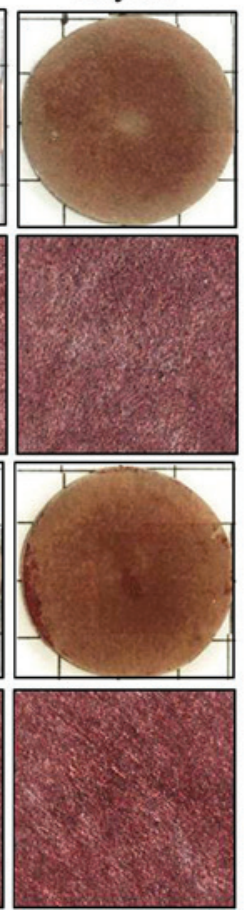

B

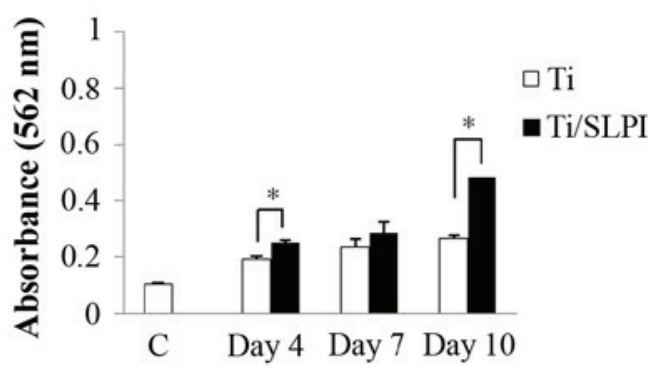

Figure 3. Determination of SLPI-treated MC3T3-E1 cell mineralization on a Ti disc. (A) Alizarin Red S staining showed that the SLPI-treated MC3T3-E1 cells exhibited higher mineral deposition on a Ti disc than the control (scale bars, $1 \mathrm{~mm}$; magnification, $\mathrm{x} 8$ or $\mathrm{x} 40$ as indicated). (B) Quantification of Alizarin Red S staining demonstrated a significant increase in SLPI-treated MC3T3-E1 cells compared with that of the control (days 4 and 10) (*P<0.05). SLPI, secretory leukocyte protease inhibitor; Ti, titanium; C, undifferentiated MC3T3-E1 cells without SLPI treatment on Ti discs (control).

effective nanomolecule for successful implantation through an increase in osteoblast adhesion and proliferation on a Ti surface (13). In addition, SLPI increases the cell viability of pancreatic cancer cells by inhibiting apoptosis (14). In this study, the level of SLPI-treated MC3T3-E1 cell proliferation was higher than that of the control during differentiation, and SLPI mRNA and protein expression was significantly higher in the SLPI-treated MC3T3-E1 cells. Therefore, SLPI increases the viability of osteoblasts during differentiation on a Ti surface.
Bone morphogenic protein, fibroblast growth factor 2 (FGF2) and transforming growth factor- $\beta 1$ (TGF- $\beta 1$ ) stimulate mineralization and bone marrow mesenchymal stem cell (BMSC) differentiation into osteoblasts. BMP-2 increases the ALP activity in BMSCs and also stimulates differentiation into osteoblasts and mineralization (15). In addition, BMP-2 increases DSPP, BSP and DMP1 mRNA expression and mineralization in dental pulp stem cells (16). Furthermore, BMP-2 treatment increases the differentiation of osteoblasts on a $\mathrm{Ti}$ surface by increasing the ALP activity (6). FGF2 stimulates 

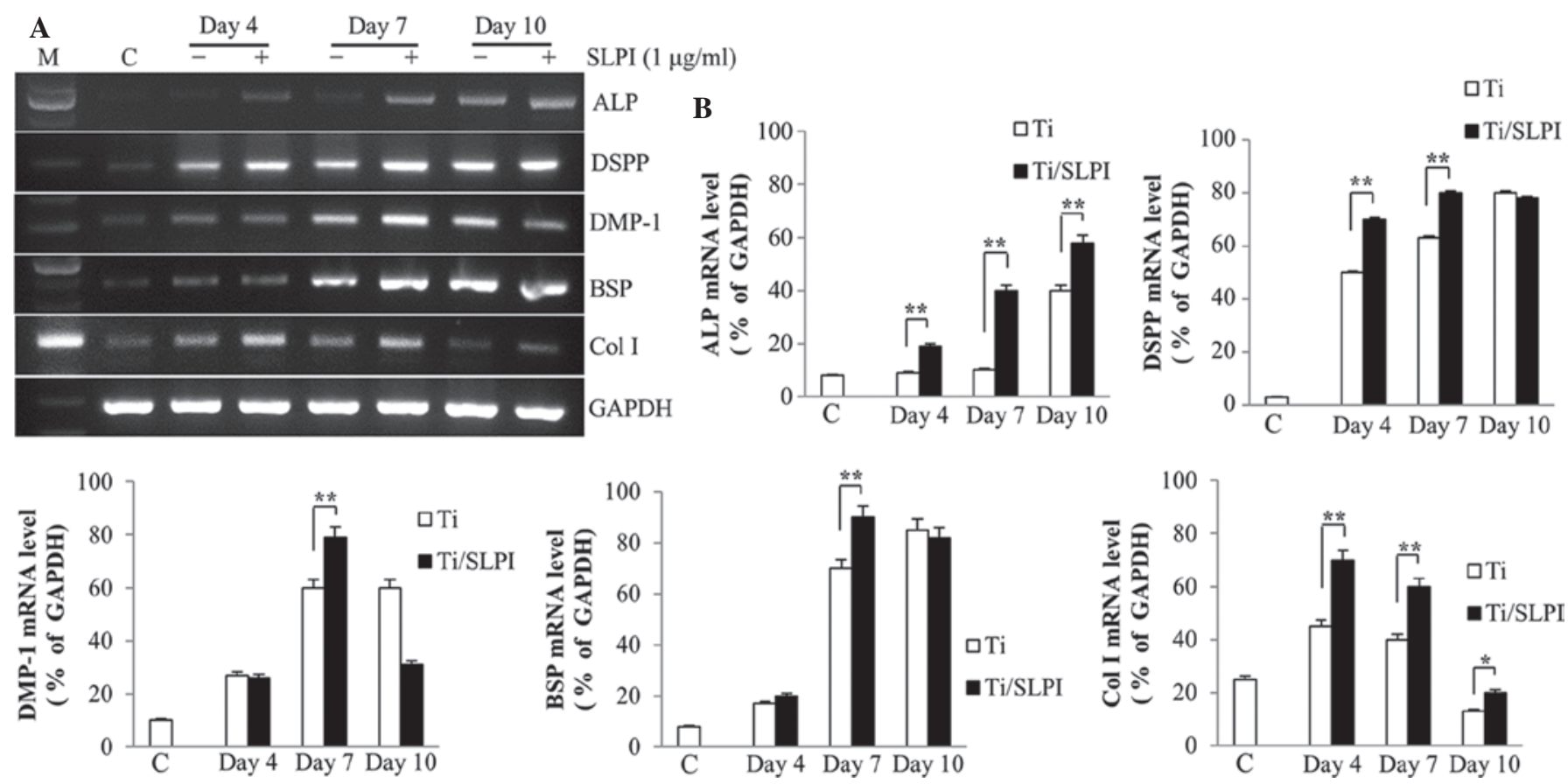

Figure 4. Expression of non-collagenous and collagenous genes in SLPI-treated MC3T3-E1 cells during differentiation on Ti discs. (A) SLPI increased the ALP, DSPP, DMP-1, BSP and Col I mRNA expression in MC3T3-E1 cells compared with that of the control during differentiation on Ti discs. (B) Quantification of polymerase chain reaction results ( $\left.{ }^{* *} \mathrm{P}<0.01\right)$. SLPI, secretory leukocyte protease inhibitor; Ti, titanium; ALP, alkaline phosphatase; DSPP, dentin sialophosphoprotein; DMP-1, dentin matrix protein 1; BSP, bone sialoprotein; Col I, collagen I; GAPDH, glyceraldehyde 3-phosphate dehydrogenase; C, undifferentiated MC3T3-E1 cells without SLPI treatment on Ti discs (control).

proliferation and differentiation and increases Col I and BSP mRNA expression and differentiation of BMSCs (17). Calcium deposition is increased during osteoblast differentiation on the Ti surface and the expression of ALP and Col I is increased at the early stages of differentiation by TGF- $\beta 1$ treatment (18). In a recent study, SLPI mRNA and protein expression was increased in the odontoblast layer of the tooth germ cell during dentinogenesis, and the formation of mineralized nodules was increased compared with that of the control in MDPC-23 cells (an odontoblastic cell line) by an SLPI treatment (19).

ALP is an essential enzyme at the early stages of osteoblast differentiation and it increases gene expression associated with osteoblast differentiation, such as Col I and osteopontin (20). DSPP, an odontoblast-specific gene, is secreted by odontoblasts and then processed proteolytically into DSP and DPP proteins during the formation of predentin (21). DPP activates the initiation of hydroxyapatite formation during dentinogenesis, and DSP regulates the initiation of dentin mineralization $(22,23)$. In addition, the expression of DSPP was identified in the osteogenic cell lines, such as MC3T3-E1 and ROS 17/2.8, as well as odontoblasts (24). DMP1 increases the formation of bone nodules and mineralization as the nucleator of hydroxyapatite (25). Among the factors associated with differentiation and mineralization, BSP is one of the component proteins in mineralized tissue, such as bone, dentin, cementum, and calcified cartilage (26). BSP acts as a nucleator of early apatite crystal formation and regulates the direction of crystal growth to form ribbon-like apatite crystals during the mineralization process (27). Col I is an important protein in bone that triggers the differentiation of osteoblasts and the level of Col I mRNA expression is decreased in MC3T3-E1 cells during mineralization (28). In this study, SLPI increased the expression of

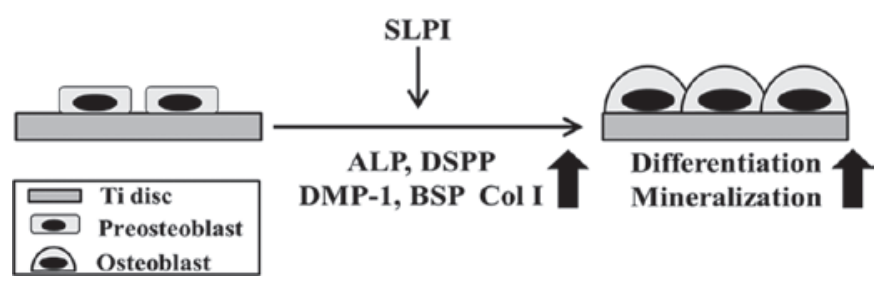

Figure 5. Schematic diagram illustrating the beneficial effects of SLPI on osteoblastogenesis and mineralization on Ti discs. SLPI increases the cell viability and differentiation of preosteoblasts during osteoblastogenesis, and increases the expression of ALP, DSPP, DMP-1, BSP, and Col I during the mineralization of osteoblasts. SLPI, secretory leukocyte protease inhibitor; ALP, alkaline phosphatase; DSPP, dentin sialophosphoprotein; DMP-1, dentin matrix protein 1; BSP, bone sialoprotein; Col I, collagen I.

ALP, DSPP, DMP-1, BSP and Col I mRNA in MC3T3-E1 cells associated with the formation of mineralized nodules compared with that of the control during differentiation on a Ti surface. A comparison of the present results with other studies indicates that SLPI can promote the differentiation and mineralization of MC3T3-E1 cells on a Ti surface. In previous studies, SLPI was shown to increase MC3T3-E1 cell adhesion to a Ti-surface as well as the proliferation of KB human oral carcinoma cells $(9,13)$. In addition, SLPI was reported to increase mineralized nodule formation and expression of BSP, DSPP, osteocalsin, osteonectin and Col I, which are associated with odontoblast differentiation and mineralization, thereby acting as a stimulant of these processes (19).

The present study was the first to report the function of SLPI in osteoblast differentiation and mineralization on a Ti surface. Previous studies have shown that SLPI regulates the formation of dentin and mineralization of odontoblasts, and 
that SLPI increases the adhesion and viability of pre-osteoblasts on a Ti surface. The present study revealed that SLPI increases the viability and differentiation of pre-osteoblasts during osteoblastogenesis and stimulates mineralization through the upregulation of ALP, DSPP, DMP1, BSP and Col I expression on a Ti surface (Fig. 5). At present, the most important challenge in implant fixation is the osseointegration between osteoblasts and a Ti surface. Therefore, the action of SLPI during mineralization and differentiation of pre-osteoblasts can reduce failure of osseointegration and consequently increase the success rate of implantation. This suggested that SLPI may be an effective adjuvant for clinically successful implantation by increasing the osseointegration on a $\mathrm{Ti}$ surface after implant placement. The findings of the present study strongly indicated that SLPI regulates the expression of factors involved in the formation of bone matrix in osteoblasts. While the signal transduction pathways of the involvement of SLPI in the differentiation and mineralization in osteoblastic cells may be further elucidated, the evidence provided by the present study suggests that an in vivo study may be due to test the efficacy of SLPI in improving dental implantation in an animal system.

\section{Acknowledgements}

This study was supported by the National Research Foundation of Korea (NRF) funded by the Ministry of Science, ICT \& Future Planning (grant no. R13-2008-010-01001-0).

\section{References}

1. Klumpers DD, Zhao X, Mooney DJ and Smit TH: Cell mediated contraction in 3D cell-matrix constructs leads to spatially regulated osteogenic differentiation. Integr Biol (Camb) 5: 1174-1183, 2013.

2. Narayanan K, Ramachandran A, Hao J, He G, Park KW, Cho M and George A: Dual functional roles of dentin matrix protein 1. Implications in biomineralization and gene transcription by activation of intracellular $\mathrm{Ca}^{2+}$ store. J Biol Chem 278: 17500-17508, 2003.

3. Kokubo T, Pattanayak DK, Yamaguchi S, Takadama H, Matsushita T, Kawai T, Takemoto M, Fujibayashi S and Nakamura T: Positively charged bioactive Ti metal prepared by simple chemical and heat treatments. J R Soc Interface 7 (Suppl 5): S503-S513, 2010.

4. Anner R, Grossmann Y, Anner Y and Levin L: Smoking, diabetes mellitus, periodontitis and supportive periodontal treatment as factors associated with dental implant survival: A long-term retrospective evaluation of patients followed for up to 10 years. Implant Dent 19: 57-64, 2010.

5. Vandrovcova M, Jirka I, Novotna K, Lisa V, Frank O, Kolska Z, Stary V and Bacakova L: Interaction of human osteoblast-like Saos-2 and MG-63 cells with thermally oxidized surfaces of a titanium-niobium alloy. PLoS One 9: e100475, 2014.

6. Olivares-Navarrete R, Hyzy SL, Pan Q, Dunn G, Williams JK, SchwartzZ and Boyan BD: Osteoblast maturation on microtextured titanium involves paracrine regulation of bone morphogenetic protein signaling. J Biomed Mater Res A 103: 1721-1731, 2015.

7. Thompson $\mathrm{RC}$ and Ohlsson $\mathrm{K}$ : Isolation, properties, and complete amino acid sequence of human secretory leukocyte protease inhibitor, a potent inhibitor of leukocyte elastase. Proc Natl Acad Sci USA 83: 6692-6696, 1986.

8. Choi BD, Jeong SJ, Wang G, Kim HJ, Kim BO, Hwang HK, Lim DS, Kim SH and Jeong MJ: Temporal induction of secretory leukocyte protease inhibitor (SLPI) in odontoblasts by lipopolysaccharide and wound infection. J Endod 35: 997-1002, 2009.
9. Jeong SJ, Wang G, Choi BD, Hwang YH, Kim BH, Ko YM and Jeong MJ: Secretory leukocyte protease inhibitor (SLPI) increases focal adhesion in MC3T3-E1 osteoblast on titanium surface. J Nanosci Nanotechnol 15: 200-204, 2015.

10. Bao Y, Geng Y and Jing H: Effect of hirudin on the levels of acute lung injury rat tumor necrosis factor- $\alpha$ and matrix metalloproteinase-12. Mol Med Rep 5: 873-875, 2012.

11. Li Y, Wong C, Xiong J, Hodgson P and Wen C: Cytotoxicity of titanium and titanium alloying elements. J Dent Res 89: 493-497, 2010.

12. Pioletti DP, Leoni L, Genini D, Takei H, Du P and Corbeil J: Gene expression analysis of osteoblastic cells contacted by orthopedic implant particles. J Biomed Mater Res 61: 408-420, 2002.

13. Wang G, Lim DS, Choi BD, Park JJ, Jeong SJ, Kim JS, Kim JD, Park JS, Kim EK, Kim BH, et al: Effect of secretory leukocyte protease inhibitor on migration and invasion of human KB oral carcinoma cells. Anim Cells Syst 15: 139-146, 2011.

14. Zuo J, Zhang C, Ren C, Pang D, Li Y, Xie X, Tang Z and Jiang X: Secretory leukocyte protease inhibitor is a proliferation and survival factor for pancreatic cancer cells. Clin Transl Oncol 17: 314-321, 2014.

15. Kim JY, Kim MR and Kim SJ: Modulation of osteoblastic/odontoblastic differentiation of adult mesenchymal stem cells through gene introduction: A brief review. J Korean Assoc Oral Maxillofac Surg 39: 55-62, 2013.

16. Yang X, van der Kraan PM, Bian Z, Fan M, Walboomers XF and Jansen JA: Mineralized tissue formation by BMP2-transfected pulp stem cells. J Dent Res 88: 1020-1025, 2009.

17. Oh SA, Lee HY, Lee JH, Kim TH, Jang JH, Kim HW and Wall I: Collagen three-dimensional hydrogel matrix carrying basic fibroblast growth factor for the cultivation of mesenchymal stem cells and osteogenic differentiation. Tissue Eng Part A 18: 1087-1100, 2012

18. Zhang H, Ahmad M and Gronowicz G: Effects of transforming growth factor-beta 1 (TGF-beta1) on in vitro mineralization of human osteoblasts on implant materials. Biomaterials 24: 2013-2020, 2003.

19. Jeong JO, Wang G, Jeong SJ, Choi BD, Lee HY and Jeong MJ: Function of secretory leukocyte protease inhibitor (SLPI) in odontoblast during mouse tooth development. J Nanosci Nanotechnol 15: 120-124, 2015.

20. Kim MB, Song Y and Hwang JK: Kirenol stimulates osteoblast differentiation through activation of the BMP and Wnt $/ \beta$-catenin signaling pathways in MC3T3-E1 cells. Fitoterapia 98: 59-65, 2014.

21. George A, Bannon L, Sabsay B, Dillon JW, Malone J, Veis A, Jenkins NA, Gilbert DJ and Copeland NG: The carboxyl-terminal domain of phosphophoryn contains unique extended triplet amino acid repeat sequences forming ordered carboxyl-phosphate interaction ridges that may be essential in the biomineralization process. J Biol Chem 271: 32869-32873, 1996.

22. Saito T, Arsenault AL, Yamauchi M, Kuboki Y and Crenshaw MA: Mineral induction by immobilized phosphoproteins. Bone 21: 305-311, 1997.

23. Suzuki S, Haruyama N, Nishimura F and Kulkarni AB: Dentin sialophosphoprotein and dentin matrix protein-1: Two highly phosphorylated proteins in mineralized tissues. Arch Oral Biol 57: 1165-1175, 2012.

24. Qin C, Brunn JC, Cadena E, Ridall A and Butler WT: Dentin sialoprotein in bone and dentin sialophosphoprotein gene expressed by osteoblasts. Connect Tissue Res 44 (Suppl 1): S179-S183, 2003.

25. He G, Dahl T, Veis A and George A: Nucleation of apatite crystals in vitro by self-assembled dentin matrix protein 1 . Nat Mater 2: 552-558, 2003.

26. Macneil RL, Sheng N, Strayhorn C, Fisher LW and Somerman MJ: Bone sialoprotein is localized to the root surface during cementogenesis. J Bone Miner Res 9: 1597-1606, 1994.

27. Hunter GK and Goldberg HA: Modulation of crystal formation by bone phosphoproteins: Role of glutamic acid-rich sequences in the nucleation of hydroxyapatite by bone sialoprotein. Biochem J 302: 175-179, 1994.

28. Quarles LD, Yohay DA, Lever LW, Caton R and Wenstrup RJ: Distinct proliferative and differentiated stages of murine MC3T3-E1 cells in culture: An in vitro model of osteoblast development. J Bone Miner Res 7: 683-692, 1992. 